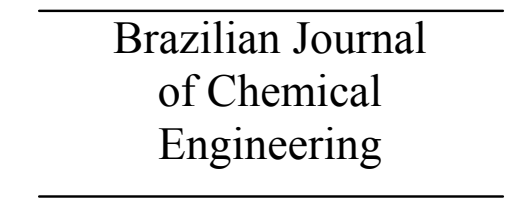

ISSN 0104-6632

Printed in Brazil

www.abeq.org.br/bjche

Vol. 29, No. 02, pp. 385 - 392, April - June, 2012

\title{
DETERMINATION OF THE MAXIMUM RETENTION OF COBALT BY ION EXCHANGE IN H-ZEOLITES
}

\author{
A. S. Zola ${ }^{1}$, M. A. S. D. Barros ${ }^{1}$, E. F. Sousa-Aguiar ${ }^{2}$ and P. A. Arroyo ${ }^{1 *}$ \\ ${ }^{1}$ Chemical Engineering Department, State University of Maringá, Phone: + (55) (44) 30114758, \\ Fax: + (55) (44) 30114792, Av. Colombo 5790, 87020-900, Maringá - PR, Brazil. \\ E-mail: arroyo@deq.uem.br \\ ${ }^{2}$ PETROBRAS/CENPES/PDEDS/ER, Av. Jequitibá 950, 21941-589, Rio de Janeiro - RJ, Brazil.
}

(Submitted: September 15, 2010 ; Revised: September 8, 2011 ; Accepted: September 27, 2011)

\begin{abstract}
This work aimed to determine the maximum content of cobalt that can be incorporated by ion exchange in zeolites H-USY, H-Beta, H-Mordenite, and H-ZSM-5. To reach this goal, batch isotherms at $75^{\circ} \mathrm{C}$ were constructed after addition of zeolite samples in flasks filled with cobalt nitrate solution. The equilibrium data were fitted to Langmuir, Freundlich, and Tóth adsorption isotherm models. Langmuir was the best model for zeolites H-Beta, H-Mordenite, and H-ZSM-5, whereas experimental data for H-USY were better fitted to the Freundlich isotherm model. From the isotherms, it was possible to determine the maximum cobalt exchange level $\left(\mathrm{q}_{\max }\right)$ that can be incorporated in each zeolite through ion exchange. In this sense, H-USY presented the highest $\mathrm{q}_{\max }$ value $\left(2.40 \mathrm{meq} / \mathrm{g}_{\text {zeol }}\right)$, while H-ZSM-5 showed the lowest one $\left(0.64 \mathrm{meq} / \mathrm{g}_{\text {zeol }}\right)$. These results also show the influence of the zeolite framework related to the channel system, pore opening, presence of cavities and secondary porosity and $\mathrm{SiO}_{2} / \mathrm{Al}_{2} \mathrm{O}_{3}$ ratio (SAR) on the maximum capacity and behavior of cobalt ion exchange in protonic zeolites.

Keywords: Cobalt; Ion exchange; Isotherms; $\mathrm{q}_{\max }$; Protonic zeolite.
\end{abstract}

\section{INTRODUCTION}

Co-zeolites have been shown to catalyze a wide range of organic reactions, including some environmentally friendly processes. Many studies have reported Co-zeolites obtained specifically from acid zeolites. This is probably due to the fact that, in this case, zeolites presented a better catalytic activity when compared to the directly exchanged cobalt zeolites (Gutierrez et al., 2007; Pedrosa et al., 2006; Chupin et al., 2006; Mies et al., 2007; Lónyi et al., 2007; Li and Armor, 1999, Zola et al, 2007). The most investigated Co-zeolites used in organic reactions are Co-ZSM-5 (Chupin et al., 2006), CoBeta (Mies et al., 2007), Co-Mordenite (Lónyi et al., 2007) and Co-USY (Li and Armor, 1999). One example is the Fischer-Tropsch Synthesis (FTS) to hydrogenate CO (Zola et al., 2007). The small Co metal particle confined in the zeolite framework is one of the most important parameters, as well as the shape selectivity of the zeolite and the presence of acid sites. These three parameters may easily influence the selectivity and activity of $\mathrm{CO}$ hydrogenation (Guczi and Kiricsi, 1999, Zola et al., 2007).

According to Tang et al. (2004) and Wang et al. (2005), introduction of cobalt ions into zeolites by ion exchange, followed by reduction with sodium hydroxide, is the most convenient method for synthesis of metal nanoparticles encapsulated in zeolites. In this way, the ion exchange method can provide cobalt cations in the pores or cages of a zeolite (Tang et al., 2004). The smaller cobalt nanoparticles encapsulated inside these pores or

*To whom correspondence should be addressed 
cages can exhibit high $\mathrm{CO}$ conversion in the FischerTropsch Synthesis (Wang et al., 2005).

Usually estimation of the maximum cobalt loading is based on the $\mathrm{SiO}_{2} / \mathrm{Al}_{2} \mathrm{O}_{3}$ ratio (SAR), which represents the theoretical cation exchange capacity (CEC) of the zeolite framework. However, it does not provide the real cation exchange capacity because there are inaccessible or hindered cationic sites in the zeolite structure. Thus, it becomes important to study cobalt ion exchange, before catalyst preparation, in order to determine the real maximum content of cation that can be incorporated into the zeolite by ion exchange. This procedure allows choosing the appropriate zeolitic support or the cobalt content that can be incorporated into different zeolites.

Since previous research has focused on catalysis itself and location and state of Co (Khodakov et al., 2007; Park et al., 2004; Mhamdi et al., 2009; Dědečk and Wichterlová, 1999; Dědečk et al., 2000; Dědečk et al., 2002) using mainly spectroscopic techniques, the ion exchange isotherms have hardly been studied (Guczi and Kiricsi, 1999). Therefore, this work aimed to determine the maximum content of cobalt ions that can be incorporated into the protonic zeolites Beta, Mordenite, USY and ZSM-5 by ion exchange. To accomplish this goal, the first step was to obtain the experimental equilibrium data at $75^{\circ} \mathrm{C}$. These data were adjusted to the isotherm models of Langmuir, Freundlich and Tóth. The best isotherm model then allowed the estimation of the maximum retention capacity $\left(\mathrm{q}_{\max }\right)$. These values reflect the influence of the zeolite structure and SAR on the cobalt loading and the ion exchange behavior under equilibrium conditions.

\section{EXPERIMENTAL}

\section{Zeolite Pre-Treatment}

The commercial samples of zeolites Na-ZSM-5, Na-Mordenite, H-Beta, and H-USY were generously donated by CENPES/PETROBRAS - Brazil. The $\mathrm{SiO}_{2} / \mathrm{Al}_{2} \mathrm{O}_{3}$ molar ratios (SAR), theoretical cation exchange capacities (CEC) and textural properties are presented in Table 1.

Before cobalt ion exchange, the zeolites ZSM-5 and Mordenite were converted to their protonic form. Hence, Na-ZSM- 5 was pre-treated by contacting the powdered material with an aqueous solution of $2 \mathrm{~mol} / \mathrm{L} \mathrm{NH}_{4} \mathrm{Cl}\left(\mathrm{NH}_{4}{ }^{+} / \mathrm{Al}^{3+}=7\right)$ at $70^{\circ} \mathrm{C} / 1 \mathrm{~h}$, under stirring. During the filtration process, the zeolite was submitted to a new exchange procedure by the addition of ammonium solution on the filtration cake. The solid was exhaustively washed with deionized water, dried overnight, and calcined at $500^{\circ} \mathrm{C} / 3 \mathrm{~h}$, in order to obtain the H-ZSM-5 sample. The H-Mordenite sample was prepared by an aqueous ion-exchange method involving continuous addition of $0.5 \mathrm{~mol} / \mathrm{L} \mathrm{HCl}$ to Na-Mordenite $\left(\mathrm{H}^{+} / \mathrm{Na}^{+}=2.0\right)$ on a filtration cake at room temperature. The resultant ion-exchanged zeolite was washed thoroughly with an excess of deionized water and then dried at $120^{\circ} \mathrm{C}$ overnight.

Samples of H-Beta and H-USY were used as received.

\section{Determination of the Equilibrium Time}

Determination of the equilibrium time involved the addition of $50 \mathrm{mg}$ of each H-Zeolite to different glass tubes containing $20 \mathrm{~mL}$ of $\mathrm{Co}\left(\mathrm{NO}_{3}\right)_{2} \cdot 6 \mathrm{H}_{2} \mathrm{O}$ aqueous solution $(20 \mathrm{mg} \mathrm{Co} / \mathrm{L})$ in a bath maintained at $75^{\circ} \mathrm{C}$ under constant stirring. Each tube was removed after different exchange times and the samples were filtered using a quantitative paper. The cobalt concentration in the filtrate was determined by atomic absorption spectrometry using a Varian SpectrAA 50B equipment under suitable conditions $(\lambda=240.7 \mathrm{~nm}$ and air/acetylene flame). The cobalt standards employed were prepared from stock solutions (Carlo Erba) and the samples were analyzed after incorporation using the necessary dilutions.

Table 1: Chemical composition and textural properties of the parent zeolites.

\begin{tabular}{|l|c|c|c|c|}
\hline Zeolite & $\begin{array}{c}\mathbf{S i O}_{\mathbf{2}} / \mathbf{A l}_{\mathbf{2}} \mathbf{O}_{\mathbf{3}} \\
(\mathbf{m o l a r})\end{array}$ & $\begin{array}{c}\mathbf{C E C}^{\text {* }} \\
(\mathbf{m e q} / \mathbf{g} \text { zeol) }\end{array}$ & $\begin{array}{c}\mathbf{S}_{\text {BET }} \\
\left(\mathbf{m}^{\mathbf{2}} / \mathbf{g}\right)\end{array}$ & $\begin{array}{c}\text { Micropore Volume } \\
\left(\mathbf{c m}^{\mathbf{3}} / \mathbf{g}\right)\end{array}$ \\
\hline H-Beta & 16.2 & 1.83 & 604 & 0.1794 \\
Na-Mordenite & 13.0 & 2.22 & 421 & 0.1907 \\
H-USY & 7.18 & 3.63 & 619 & 0.2852 \\
Na-ZSM-5 & 39.9 & 0.783 & 397 & 0.1783 \\
\hline
\end{tabular}

${ }^{*}$ Theoretical cation exchange capacity, based on the total aluminum content present in the zeolite structure. 


\section{Isotherm Construction}

After establishing the equilibrium time, the batch isotherms were obtained for each zeolite studied. Tests were carried out by the addition of the zeolite mass $(0.01$ up to $1.50 \mathrm{~g})$ to glass tubes already filled with $20 \mathrm{~mL}$ of the cobalt solution. The system was maintained at $75^{\circ} \mathrm{C}$ under constant stirring. When the equilibrium time was attained, samples were filtered and the cobalt concentration in the liquid phase was analyzed by atomic absorption spectrometry as described above.

Several authors have used adsorption models to describe experimental data for ion exchange in zeolites and other materials (Misak, 1995; Malekian et al., 2010; Ostroski et al., 2009; Al-Anber and Al-Anber, 2008, Silva et al., 2003, Torab-Mostaedi et al., 2010, Senthil Kumar et al., 2010, Mousavi et al., 2010). In applying such models, one should bear in mind that the ion exchange process is the most important sorption mechanism although the subsequent adsorption phenomena should not be neglected.

The software ORIGIN $7.5^{\circledR}$ was used to adjust the experimental equilibrium data to the isotherm models described below:

\section{1) Freundlich isotherm}

$q=K^{\prime} C^{1 / n}$

where: $\mathrm{q}$ is the amount adsorbed at equilibrium per amount of adsorbent (meq/g);

$\mathrm{C}$ is the equilibrium concentration $(\mathrm{meq} / \mathrm{L})$ of the adsorbate in the solution;

$\mathrm{K}^{\prime}(\mathrm{L} / \mathrm{g})$ and $1 / \mathrm{n}$ (dimensionless) are constants depending on several experimental factors associated with the active site distribution and the adsorbent capacity (Suzuki, 1990; Maheria and Chudasama, 2006).

2) Langmuir isotherm

$$
q=\frac{q_{\max } b C}{1+b C}
$$

where: $\mathrm{C}$ and $\mathrm{q}$ have the same meaning as described for the Freundlich isotherm;

$\mathrm{b}$ is a constant that represents the adsorption bond energy (L/meq);

$\mathrm{q}_{\max }$ is a constant that represent the maximum adsorption capacity (meq/g), corresponding to a monolayer covering the surface of the adsorbent (Maheria and Chudasama, 2006; Pereira et al., 2006).

Although the assumptions of the Langmuir model are related to the adsorption process, the mathematical equation has been prominently used in ion exchange process (Helferich, 1962). Indeed, successful mathematical approaches have been used (Misak, 1995), even for zeolites (Helferich, 1962).

Rengaraj and Moon (2002) proposed that the essential characteristics of the Langmuir isotherm could be expressed in terms of a dimensionless constant or equilibrium parameter $\left(\mathrm{R}_{\mathrm{L}}\right)$, which is defined as:

$\mathrm{R}_{\mathrm{L}}=\frac{1}{(1+\mathrm{bCo})}$

where: $b$ is the Langmuir constant $(\mathrm{L} / \mathrm{meq})$;

$\mathrm{Co}$ is the initial concentration of cobalt (meq/L).

3) Tóth isotherm

$q=\frac{q_{m} C}{\left(\frac{1}{K_{m}}+C^{m}\right)^{1 / m}}$

where: $\mathrm{q}_{\mathrm{m}}$ is the maximum adsorption capacity (meq $/ \mathrm{g}$ );

$\mathrm{C}$ has the same meaning as described for the Freundlich isotherm;

$\mathrm{K}_{\mathrm{m}}$ is the equilibrium constant;

$\mathrm{m}$ is the model constant.

\section{RESULTS AND DISCUSSION}

The concentration of cobalt in solution as a function of ion exchange time is shown in Figure 1. As can be observed, the ion exchange equilibrium is reached at about $36 \mathrm{~h}$ of ion exchange for all H-Zeolites studied. However, to ensure that the ion exchange equilibrium was actually reached, a three-day period was adopted for the ion exchange process.

The equilibrium results, as well as the model adjustments, are presented in Figure 2.

All fitted models for the $\mathrm{H}$-Zeolite systems presented favorable shape (McCabe et al., 2001). According to the classification system for adsorption isotherms proposed by Giles et al. (1960), all experimental data are of the $\mathrm{S}$ type, indicating the horizontal orientation of cobalt molecules on the zeolitic surface. These observed shapes could be related to the octahedral geometry of $\mathrm{Co}^{2+}$ ions (Dědečk and Wichterlová, 1999; Dědečk et al., 2000; Dědečk et al., 2002). The accommodation of $\mathrm{Co}^{2+}$ ions seems to form layers until the isotherm plateau, when it becomes more stable. Such a plateau is not well defined due to the rapid adsorption process in multilayers. The adsorption layers would be formed starting from the moment that, due to the electrostatics attraction of the zeolite with $\mathrm{Co}^{2+}$ ions, there is a new accommodation, and the in-going cobalt ions are 
present in vertical form. Then, the multilayer adsorption occurs as the monolayer, reflecting the strongest ion exchange process, becomes more and more crowded. This fact explains the sigmoid shape of the isotherms with inflexion points at different $\mathrm{q}$ values corresponding to the difficulty of $\mathrm{Co}^{2+}$ in occupying different sites located in the zeolite channels and cavities. This behavior is more pronounced for the H-USY system, in which some cobalt cations are exchanged into less accessible sites located in sodalite and hexagonal prisms cages (Barros et al., 2003a,b).

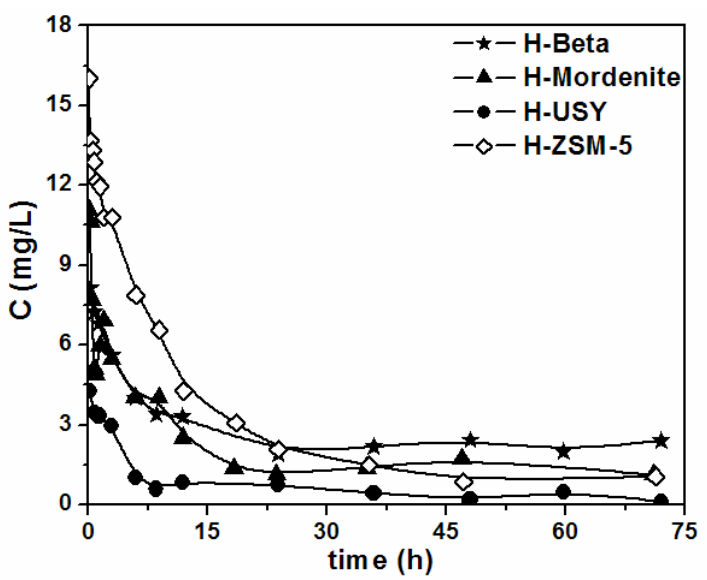

Figure 1: Determination of the equilibrium time for cobalt ion exchange in $\mathrm{H}$-Zeolites at $75^{\circ} \mathrm{C}$.
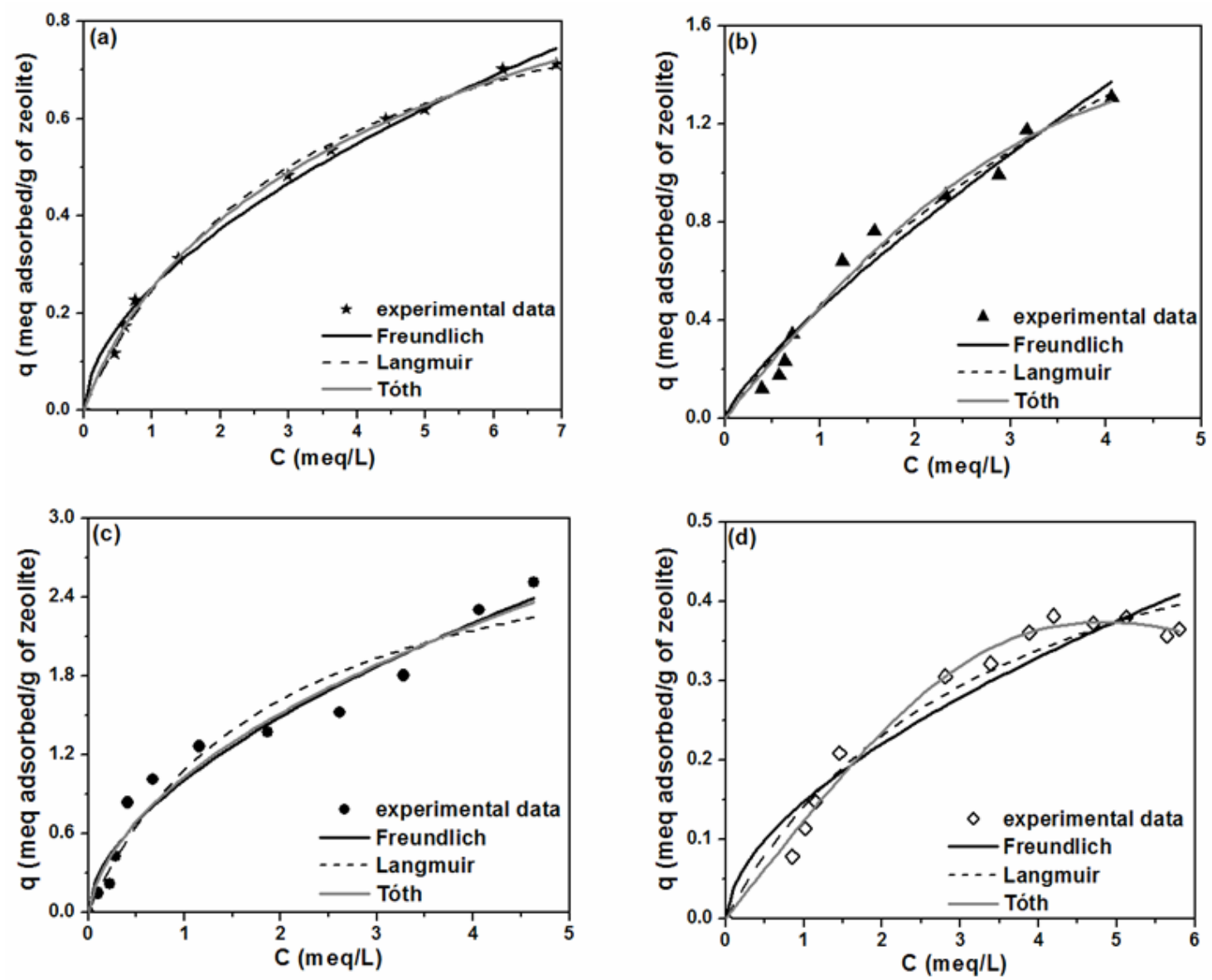

Figure 2: Isotherms obtained at $75^{\circ} \mathrm{C}$ for ion exchange in zeolites: (a) H-Beta; (b) H-Mordenite; (c) H-USY; and (d) H-ZSM-5. 
Table 2 presents the isotherm parameters for the models investigated here.

It can be verified that the Tóth isotherm showed the highest correlation coefficient values for all zeolites, as expected, since it is a three-parameter model. However, the errors associated with the model parameters were very high, exceeding the value of the parameter itself. Considering such analysis, the Langmuir model was the most representative of the equilibrium data at $75^{\circ} \mathrm{C}$ for zeolites H-Beta, H-Mordenite, and H-ZSM-5. On the other hand, the Freundlich model presented the best fit for the H-USY system.

The dimensionless separation factor $\left(\mathrm{R}_{\mathrm{L}}\right)$ values, obtained from the Langmuir isotherm parameters (Eq. (3)), were 0.016, 0.013, and 0.018 for H-Beta, H-Mordenite, and H-ZSM-5, respectively. According to Rangaraj and Moon (2002), values between 0 and 1 confirm the favorable cobalt uptake, which is in agreement with the experimental equilibrium data already shown.

The Freundlich isotherm describes reversible adsorption and is not restricted to the formation of a monolayer, as might indicate the Langmuir model. Further, the Freundlich model predicts that the cobalt concentration in the zeolite will increase steadily with increasing cobalt concentration in the liquid phase (Hameed et al., 2007). As the Freundlich model was the most representative for the H-USY system, it suggests that initially there is a cobalt exchange with $\mathrm{H}^{+}$ions in the accessible supercages and then an increase of ion exchange with parent ions located in the sodalite units and some less accessible hexagonal prisms at higher external cobalt concentrations (Kim and Keane, 2000). These ion exchange conditions lead to a favorable behavior that is represented by an exponent $\mathrm{n}$ higher than 1 for zeolite H-USY (Rengaraj and Moon, 2002).

From the best-fit isotherm models, it was possible to determine the $\mathrm{q}_{\max }$ values, i.e., the maximum amount of cobalt that can be exchanged per gram of H-Zeolite (except USY). The values obtained for each zeolite and the maximum content of cobalt that can be theoretically incorporated by ion exchange are presented in Table 3.

It can be observed in Table 3 that H-ZSM-5 presents the smallest amount of cobalt incorporated. In fact, it is the only zeolite studied that presents medium micropores and a bi-dimensional channel system, whose openings are $5.1 \times 5.7$ and 5.4 x $5.6 \AA$ (Gianneto-Pace et al., 2000), while the other zeolites possess large micropores. As the H-ZSM-5 pore opening is small, the entrance of the cobalt cation, which has a hydrated radius of $4.23 \AA$, is hindered. Furthermore, it should be taken into account that low valence cations are preferred by zeolites of higher SAR (Townsend, 1991). Zeolite H-ZSM-5 has a higher SAR of 39.9, corresponding to a CEC of $0.783 \mathrm{meq} / \mathrm{gzeol}$, which is much smaller than those of the other zeolites. Therefore, this feature could lead to a lower preference and retention capacity of H-ZSM-5 for $\mathrm{Co}^{2+}$ cations, which is in agreement with the values presented in Table 3 .

Table 2: Estimated isotherm parameters and correlation values for Co ion exchange in $\mathrm{H}-\mathrm{Zeolites}$ at $75^{\circ} \mathrm{C}$.

\begin{tabular}{|c|c|c|c|c|}
\hline \multirow{2}{*}{ Model } & \multicolumn{4}{|c|}{ Zeolite } \\
\hline & H-Beta & H-Mordenite & H-USY & H-ZSM-5 \\
\hline \multirow{3}{*}{ Langmuir } & $\mathrm{R}^{2}=0.9941$ & $\mathrm{R}^{2}=0.9800$ & $\mathrm{R}^{2}=0.9369$ & $\mathrm{R}^{2}=0.9607$ \\
\hline & $\mathrm{b}=0.30 \pm 0.03$ & $\mathrm{~b}=0.39 \pm 0.10$ & $\mathrm{~b}=0.44 \pm 0.18$ & $\mathrm{~b}=0.28 \pm 0.07$ \\
\hline & $\mathrm{q}_{\max }=1.06 \pm 0.05$ & $\mathrm{q}_{\max }=1.43 \pm 0.17$ & $\mathrm{q}_{\max }=3.62 \pm 0.73$ & $\mathrm{q}_{\max }=0.64 \pm 0.08$ \\
\hline \multirow{3}{*}{ Freundlich } & $\mathrm{R}^{2}=0.9905$ & $\mathrm{R}^{2}=0.9736$ & $\mathrm{R}^{2}=0.9580$ & $R^{2}=0.9332$ \\
\hline & $\mathrm{n}=1.77 \pm 0.09$ & $\mathrm{n}=1.74 \pm 0.19$ & $\mathrm{n}=1.63 \pm 0.17$ & $\mathrm{n}=1.72 \pm 0.23$ \\
\hline & $\mathrm{K}^{\prime}=0.25 \pm 0.01$ & $\mathrm{~K}^{\prime}=0.4 \pm 0.03$ & $\mathrm{~K}^{\prime}=1.03 \pm 0.07$ & $\mathrm{~K}^{\prime}=0.15 \pm 0.02$ \\
\hline \multirow{4}{*}{ Tóth } & $\mathrm{R}^{2}=0.9951$ & $\mathrm{R}^{2}=0.9804$ & $\mathrm{R}^{2}=0.9581$ & $\mathrm{R}^{2}=0.9877$ \\
\hline & $\mathrm{q}_{\mathrm{m}}=0.55 \pm 0.28$ & $\mathrm{q}_{\mathrm{m}}=0.99 \pm 1.28$ & $\mathrm{q}_{\mathrm{m}}=0.42 \pm 0.74$ & $\mathrm{q}_{\mathrm{m}}=36.8 \pm 39.0$ \\
\hline & $\mathrm{K}_{\mathrm{m}}=0.59 \pm 0.32$ & $\mathrm{~K}_{\mathrm{m}}=0.55 \pm 0.74$ & $\mathrm{~K}_{\mathrm{m}}=43.8 \pm 1685$ & $\mathrm{~K}_{\mathrm{m}}=0.01 \pm 0.01$ \\
\hline & $\mathrm{m}=0.80 \pm 0.14$ & $\mathrm{~m}=0.87 \pm 0.42$ & $\mathrm{~m}=0.4 \pm 0.34$ & $\mathrm{~m}=2.67 \pm 0.49$ \\
\hline
\end{tabular}

Table 3: Experimental and theoretical maximum content of cobalt ion exchange in $\mathrm{H}-\mathrm{Zeolites}$ at $75^{\circ} \mathrm{C}$.

\begin{tabular}{|l|c|c|c|c|}
\hline \multirow{2}{*}{ Zeolite } & \multicolumn{2}{|c|}{$\begin{array}{c}\text { qmax } \\
\text { (meq Co/gzeol) }\end{array}$} & \multicolumn{2}{c|}{$\begin{array}{c}\text { Maximum content of Co in zeolite } \\
\text { (wt. \%) }\end{array}$} \\
\cline { 2 - 5 } & experimental & theoretical & experimental $^{*}$ theoretical $^{*}$ \\
\hline H-Beta & 1.06 & 1.83 & 2.93 & 5.05 \\
H-Mordenite & 1.43 & 2.22 & 4.08 & 6.34 \\
H-USY & 2.40 & 3.64 & 6.47 & 9.81 \\
H-ZSM-5 & 0.64 & 0.79 & 1.86 & 2.29 \\
\hline
\end{tabular}

${ }^{*}$ Based on the total aluminum content present in the zeolite structure (CEC). 
The zeolite H-USY presented the highest cobalt content that can be incorporated by ion exchange. It is probably due to the three-dimensional pore system, the higher CEC of $3.63 \mathrm{meq} / \mathrm{gzeol}$ (smallest SAR among the zeolites studied), and the pore opening of $7.4 \AA$, that permits a quite free access into supercages $\alpha$ of $12.4 \AA$ diameter (Gianneto-Pace et al., 2000). Additionally, it is also possible that the dealumination of zeolite $\mathrm{Y}$, in the process of obtaining zeolite USY, generates a secondary porosity that allows a better access to the exchange sites located in the channels and large cavities of this structure. It justifies the smaller resistance to diffusion inside the crystals experienced by the hydrated cobalt cations present in the ion exchange solution.

Moreover, it is also possible to verify in Table 3 that the maximum capacity of cobalt incorporation into H-Mordenite is a little higher than those observed for H-Beta (4.08 wt.\% and 2.93 wt.\% of Co, respectively). Zeolites H-Beta and H-Mordenite have three-dimensional and pseudo-one-dimensional pore systems (elliptic rings with 12 oxygen atoms), respectively. Thus, an opposite tendency would be expected for the $\mathrm{q}_{\max }$ values. However, it should be considered that $\mathrm{H}$-Mordenite has a pore opening of $7.1 \times 6.7 \AA$, in contrast to the smaller openings of approximately $7.3 \times 6.0 \AA$ and 5.6 × $5.6 \AA$ for zeolite H-Beta (Gianneto-Pace et al., 2000). This fact itself would not be enough to explain such a difference. Besides, H-Mordenite presents a lower SAR (13.0) and consequently a higher CEC $(2.22 \mathrm{meq} / \mathrm{gzeol})$. Thus, a higher $\mathrm{Co}^{2+}$ retention in H-Mordenite is justified. These results evidence the influence of the zeolite structure on the ion exchange process. The channel system, the pore opening and the presence of cavities and secondary porosity may affect the maximum capacity of $\mathrm{Co}^{2+}$ retention and exchange behavior. Moreover, SAR plays an important role in determining the maximum amount of cation that can be incorporated in the zeolites by ion exchange.

Therefore, it is possible to incorporate Co contents from 1.9 wt.\% in H-ZSM-5 up to approximately 6.5 wt. $\%$ in H-USY. The high incorporation of cobalt in H-USY makes us conclude that this zeolite is a potential support for cobalt catalysts prepared by the ion exchange method.

\section{CONCLUSIONS}

The cobalt isotherms obtained at $75^{\circ} \mathrm{C}$ are favorable, showing the good affinity of the $\mathrm{H}$ Zeolites for $\mathrm{Co}^{2+}$ cations. The equilibrium data for
$\mathrm{Co}^{2+}$ ion exchange are best fitted with Langmuir isotherm model for H-Beta, H-Mordenite, and H-ZSM-5, while the Freundlich isotherm model fit the experimental data better for H-USY. The maximum cobalt contents that can be incorporated $\left(\mathrm{q}_{\max }\right)$ by ion exchange are 1.06, 1.43, 2.40 and $0.64 \mathrm{meq} \mathrm{Co} / \mathrm{gzeol}$ for H-Beta, H-Mordenite, H-USY, and H-ZSM-5, respectively, which clearly shows the influence of the zeolite structure and composition on the ion exchange process. Therefore, the maximum amount of Co cation that can be incorporated into the zeolite structure and the ion exchange behavior are strongly influenced by the $\mathrm{SiO}_{2} / \mathrm{Al}_{2} \mathrm{O}_{3}$ ratio (SAR), the channel system, the pore opening, and the presence of cavities and secondary porosity. The results obtained here also demonstrate that is necessary to determine experimentally the proper maximum value of cation exchange capacity for each zeolite system, since theoretical ion exchange capacities do not usually allow incorporation of the desired cobalt content into the zeolite support. Considering all these factors the zeolite USY presents the highest potential as an appropriate support for Co catalysts prepared by the ion exchange method.

\section{ACKNOWLEDGEMENT}

The authors thank to the $\mathrm{CNPq} / \mathrm{Brazil}$ and PROCAD/CAPES/Brazil for financial support.

\section{REFERENCES}

Al-Anber, M., Al-Anber, Z. A., Utilization of natural zeolite as ion-exchange and sorbent material in the removal of iron. Desalination, n. 225, p. 70-81 (2008).

Barros, M. A. S. D., Araújo Jr., I. F., Arroyo, P. A., Sousa-Aguiar, E. F., Tavares, C. R. G., Multicomponent ion exchange isotherms in $\mathrm{NaX}$ zeolite. Latin Am. Appl. Res., n. 33, p. 339-344 (2003a).

Barros, M. A. S. D., Zola, A. S., Arroyo, P. A., Sousa-Aguiar, E. F., Tavares, C. R. G., Binary ion exchange of metal íons in $\mathrm{Y}$ and $\mathrm{X}$ zeolites. Braz. J. Chem. Eng., v. 20, 413-421 (2003b).

Chupin, C., van Veen, A. C., Konduru, M., Després, J., Mirodatos, C., Identity and location of active species for NO reduction by $\mathrm{CH}_{4}$ over Co-ZSM-5. J. Catal., n. 241, p. 103-114 (2006).

Dědečk, J. and Wichterlová, B., $\mathrm{Co}^{2+}$ Ion Siting in Pentasil-Containing Zeolites. I. $\mathrm{Co}^{2+}$ Ion Sites and Their Occupation in Mordenite. A Vis-NIR 
diffuse reflectance spectroscopy study. J. Phys. Chem. B., n. 103, p. 1462-1476 (1999).

Dědečk, J., Čapek, L., Kaucký, D., Zobalíck, Z., Wichterlová, B., Siting and distribution of the Co ions in beta zeolite: A UV-VIS-NIR and FTIR study. J. Catal., n. 211, p. 198-207 (2002).

Dědečk, J., Kaucký, D., Wichterlová, B., $\mathrm{Co}^{2+}$ ion siting in pentasil-containing zeolites, Part 3. $\mathrm{Co}^{2+}$ ion sites and their occupation in ZSM-5: a VIS diffuse reflectance spectroscopy study. Micropor. Mesopor. Mater., n. 35-36, p. 483494 (2000).

Gianetto-Pace, G., Rendón, A. M., Fuentes, G. R., Zeolitas: Características, propiedades y aplicaciones industriales. EdIT- Editora Innovación Tecnológica, Facultad de Ingeniería, UCV, Caracas (2000). (In Spanish).

Giles, C. H., MacEwan, T. H., Nakhwa, S. N., Smith, D., Studies in adsorption. Part XI.* A system of classification of solution adsorption isotherms, and its use in diagnosis of adsorption mechanisms and in measurement of specific surface areas of solids. J. Chem. Soc., n. 111, p. 3973-3993 (1960).

Guczi, L. and Kiricsi, I., Zeolite supported monoand bimetallic systems: Structure and performance as CO hydrogenation catalysts. Appl. Catal. A: Gen., n. 186, p. 375-394 (1999).

Gutierrez, L. B., Miro, E. E., Ulla, M. A., Effect of the location of cobalt species on NO adsorption and $\mathrm{NO}_{\mathrm{x}}-\mathrm{SCR}$ over Co-mordenite. Appl. Catal. A: Gen., n. 321, p. 7-16 (2007).

Hameed, B. H., Ahmad, A. A., Aziz, N., Isotherms, kinetics and thermodynamics of acid dye adsorption on activated palm ash. Chem. Eng. J., n. 133 (1-3), p. 195-203 (2007).

Helferich, F., Ion exchange. Dover Publication, New York (1962).

Khodakov, A. Y., Chu, W., Fongariand, P., Advances in the development of novel cobalt Fischer-Tropsch synthesis of long-chain hydrocarbons and clean fuels. Chem. Rev., n. 107, p. 1692-1744 (2007).

Kim, J. S. and Keane, M. A., Ion exchange of divalent cobalt and iron with $\mathrm{Na}-\mathrm{Y}$ zeolite: binary and ternary exchange equilibria. J. Coll. Interf. Sci., n. 232, p. 126-132 (2000).

Li, Y. and Armor, J. N., Ammoxidation of ethane to acetonitrile. IV: Substantial differences between $\mathrm{Y}$ and dealuminated Y zeolite. Appl. Catal. A: Gen., n. 183, (1), p. 107-120 (1999).

Lónyi, F., Valyon, J., Gutierrez, L., Ulla, M. A., Lombardo, E. A., The SCR of $\mathrm{NO}$ with $\mathrm{CH}_{4}$ over Co-, CoPt-, and H-mordenite catalysts. Appl. Catal. B: Env., n. 173, (1-2), p. 1-10 (2007).
Maheria, K. and Chudasama, U., Studies on Kinetics, Thermodynamics and sorption characteristics of an inorganic ion exchanger - titanium phosphate towards $\mathrm{Pb}$ (II), Bi (III) and Th (IV). J. Indian Inst. Sci., n. 86, p. 515-525 (2006).

Malekian, R., Abedi-Koupai, J., Eslamian, S. S., Mousavi, S. F., Abbaspour, K. C., Afyuni, M., Ion-exchange process for ammonium removal and release using natural Iranian zeolite. Applied Clay Science, v. 51, n. 3, p. 323-329 (2010).

McCabe, W. L., Smith, J. C., Harriot, P., Unit operations of chemical engineering. 6th Ed., McGraw-Hill International Ed. (2001).

Mhamdi, M., Khaddar-Zine, S., Ghorbel, A., Influence of the cobalt salt precursors on the cobalt speciation and catalytic properties of $\mathrm{H}$ ZSM-5 modified with cobalt by solid-state ion exchange reaction. App. Catal. A: Gen., n. 357, p. 42-50 (2009).

Mies, M. J. M., Rebrow, E. V., Jansen, J. C., Croon, M. H. J. M., Schouten, J. C., Method for the in situ preparation of a single layer of zeolite beta crystals on a molybdenium substrate for microreator applications. J. Catal., n. 247, p. 328338 (2007).

Misak, N. Z., Adsorption isotherms in ion exchange reactions. Further treatments and remarks on the application of the Langmuir isotherm. Colloids and Surfaces A: Physicochemical and Engineering Aspects, n. 97, p. 129-140 (1995).

Mousavi, H. Z., Hosseynifar, A., Jahed, V., Dehghani, S. A. M., Removal of lead from aqueous solution using waste tire rubber ash as an adsorbent. Braz. J. Chem. Eng., vol. 27, n. 1, p. 79-87 (2010).

Ostroski, I. C., Barros, M. A. S. D., Silva, E. A., Dantas, J. H., Arroyo, P. A., Lima, O. C. M., A comparative study for the ion exchange of $\mathrm{Fe}(\mathrm{III})$ and $\mathrm{Zn}$ (II) on zeolite NaY. Journal of Hazardous Materials, n. 161, 2-3, p. 1404-1412 (2009).

Park, J-H., Park, C. H., Nam, I-S., Characteristics of wet and solid ion exchanged co-ferrerite catalysts for the reduction of NO using methane. App. Catal. A: Gen., n. 277, p. 271-279 (2004).

Pedrosa, A. M. G., Souza, M. J. B., Melo, D. M. A., Araújo, A. S., Cobalt and nickel supported on HY zeolite: Synthesis, characterization and catalytic properties. Mater. Res. Bull., n. 41, (6), p. 11051111 (2006).

Pereira, M. R., Arroyo, P. A., Barros, M. A. S. D., Sanches, V. M., Silva, E. A., Fonseca, I. M., Lovera, R. G., Chromium adsorption in olive stone activated carbon. Adsorption, n. 12, p. 155162 (2006). 
Rengaraj, S. and Moon, S. H., Kinetics of adsorption of Co (II) removal from water and wastewater by ion exchange resins. Wat. Res., n. 36, p. 17831793 (2002).

Senthil Kumar, P., Ramakrishnan, K., Dinesh Kirupha, S., Sivanesan, S., Thermodynamic and kinetic studies of cadmium adsorption from aqueous solution onto rice husk. Braz. J. Chem. Eng., vol. 27, n. 2, p. 347-355 (2010).

Silva, E. A., Cossich, E. S., Tavares, C. G., Cardozo Filho, L., Guirardello, R., Biosorption of binary mixtures of $\mathrm{Cr}(\mathrm{III})$ and $\mathrm{Cu}(\mathrm{II})$ ions by Sargassum sp. Braz. J. Chem. Eng., vol. 20, n. 3, p. 213-227 (2003).

Suzuki, M., Adsorption Engineering. Elsevier, Amsterdam (1990).

Tang, Q., Zhang, Q., Wang, P., Wang, Y., Wan, H., Characterizations of cobalt oxide nanoparticles within faujasite zeolites and the formation of metallic cobalt. Chem. Mater., n. 16, p. 19671976 (2004).

Torab-Mostaedi, M., Ghassabzadeh, H., GhannadiMaragheh, M., Ahmadi, S. J., H. Taheri, Removal of cadmium and nickel from aqueous solution using expanded perlite. Braz. J. Chem. Eng., vol. 27, n. 2, p. 299-308 (2010).

Townsend, R. P., Ion Exchange in Zeolites. In: E. M. Flanigen, J. C. Janson (Ed). Stud. Surf. Sci. Catal., n. 58, p. 359-390 (1991).

Wang, Y., Wu, H., Zhang, Q., Tang, Q., Cobalt Nanoparticles prepared in faujasite zeolites by borohydride reduction. Microp. Mesop. Mater., n. 86, p. 38-49 (2005).

Zola, A. S., Bidart, A. M. F., Fraga, A. C., Hori, C. E., Sousa-Aguiar, E. F., Arroyo, P. A., Cobalt supported on different zeolites for FischerTropsch synthesis. Stud. Surf. Sci. Catal., n. 167, p. 129-134 (2007). 